\title{
Microbial decontamination of human donor eyes with povidone-iodine: penetration, toxicity, and effectiveness
}

E Pels, G F J M Vrensen

\begin{abstract}
Backgroundlaims-Povidone-iodine (PVP -I) is applied for microbial decontamination of human eyes donated for transplantation. Concentrations and immersion times vary greatly. The effectiveness and toxicity of PVP-I were assessed for different decontamination protocols.
\end{abstract}

Methods-Human donor eyes and corneas were immersed in different concentrations $(5-100 \mathrm{mg} / \mathrm{ml})$ of PVP-I for different times (2-30 minutes). The penetration of iodine into the corneal tissue was assessed by $x$ ray microanalysis. Microbial contamination was determined by taking cultures of the limbal areas and storage solutions and by incubation of the corneoscleral buttons in antibiotic-free culture medium. Cytotoxicity of PVP-I for corneal fibroblasts in culture was assessed using the MTT assay.

Results-Depending on concentration and immersion time iodine was found to penetrate into the epithelium, Bowman's layer, and stroma in amounts equivalent to $2-40 \mathrm{mg} / \mathrm{ml}$ PVP-I. The MTT assay demonstrated that $2.5 \mathrm{mg} / \mathrm{ml}$ PVP-I caused total damage to fibroblasts in vitro. Rinsing eyes with tap water and subsequent immersion in PVP-I reduced the rate of contamination from 82 out of 106 to 69 out of 106 and 37 out of 106, respectively. Antibiotics in the storage medium further reduced contamination from about $40 \%$ to $3 \%$. Microbial contamination was not reduced by increasing the concentration and immersion times beyond $5 \mathrm{mg} / \mathrm{ml}$ PVP-I for 2 minutes.

Conclusion-Immersion of human donor eyes in $5 \mathrm{mg} / \mathrm{ml}$ PVP-I solution for $2 \mathrm{~min}$ utes significantly reduces microbial contamination of donor corneas without relevant penetration of iodine into the corneal layers. Higher PVP-I concentrations and longer immersion times do not further reduce contamination, whereas the amount of iodine penetrating the corneal layers is elevated above the level cytotoxic for corneal fibroblasts. In view of this, concentrations above $5 \mathrm{mg} / \mathrm{ml}$ of PVP-I and immersion periods over 2 minutes are not recommended for reduction of the contamination rate of donor eyes. (Br f Ophthalmol 1999;83:1019-1026)

All cornea banks have to cope with the problem of supplying viable donor tissue free from microbial contaminants, while donor eyes are generally contaminated. ${ }^{1-4}$ Different decontamination procedures have been advocated: (i) treatment with antibiotics, ${ }^{5-9}$ (ii) irrigation, ${ }^{10-14}$ (iii) mechanical abrasion of the epithelium, ${ }^{7}$ and (iv) immersion of eyes in povidone-iodine/ betadine. $^{9121416}$ The use of povidone-iodine (PVP-I, polyvinylpyrrolidone-iodine complex) is attractive because of its broad antimicrobial action spectrum including most Gram positive and Gram negative bacteria, fungi, yeasts, viruses, and protozoa. ${ }^{17}$ In addition, it is chemically stable, inexpensive, and readily available. For the same reasons PVP-I is suggested as treatment for corneal ulcers in cases when antibiotics are not available as, for example, in developing countries.

The concentration of "free" iodine significantly contributes to the antimicrobial activity of PVP-I. The effect of hypoiodous acid which also contributes to the antimicrobial activity of PVP-I is not considered in this paper. Dilution of PVP-I results in weakening of the iodine binding to the carrier molecule and a concomitant increase in the amount of "free" iodine in the solution. ${ }^{17}{ }^{18}$ In antiseptic practice watery solutions of $50-100 \mathrm{mg} / \mathrm{ml}$ PVP-I are commonly used. However, for decontamination of human donor eyes concentrations of 5-100 $\mathrm{mg} / \mathrm{ml}$ and immersion times of 2-10 minutes are applied by eye banks. ${ }^{19}$ Despite the reported low ocular toxicity of PVP-I ${ }^{20-22}$ some toxic effects have been described for the corneal epithelium and fibroblasts at concentrations of 25 and $50 \mathrm{mg} / \mathrm{ml}$ and immersion periods over 4 minutes. ${ }^{12}$ Recently, it has been shown that $50 \mathrm{mg} / \mathrm{ml}$ PVP-I for 3 minutes is superior to ciprofloxacin and gentamicin in antimicrobial effectiveness, but corneal tolerance of the procedure still needs investigation. ${ }^{9}$

In this study energy dispersive $x$ ray microanalysis (EDXM) was performed to investigate the penetration of iodine into the cornea and its dependence on PVP-I dose, immersion time, and intactness of the epithelial layer. In addition, the concentration dependent toxicity of PVP-I for human corneal fibroblasts was assessed using the MTT assay and was related to the amount of iodine present in the cornea. The effectiveness of different concentrations of PVP-I and immersion times for bacterial and fungal decontamination of corneoscleral buttons was evaluated.

\section{Methods}

HUMAN CORNEAS

Human eyes were donated to the Foundation BIS (Leiden, Netherlands) for transplantation 


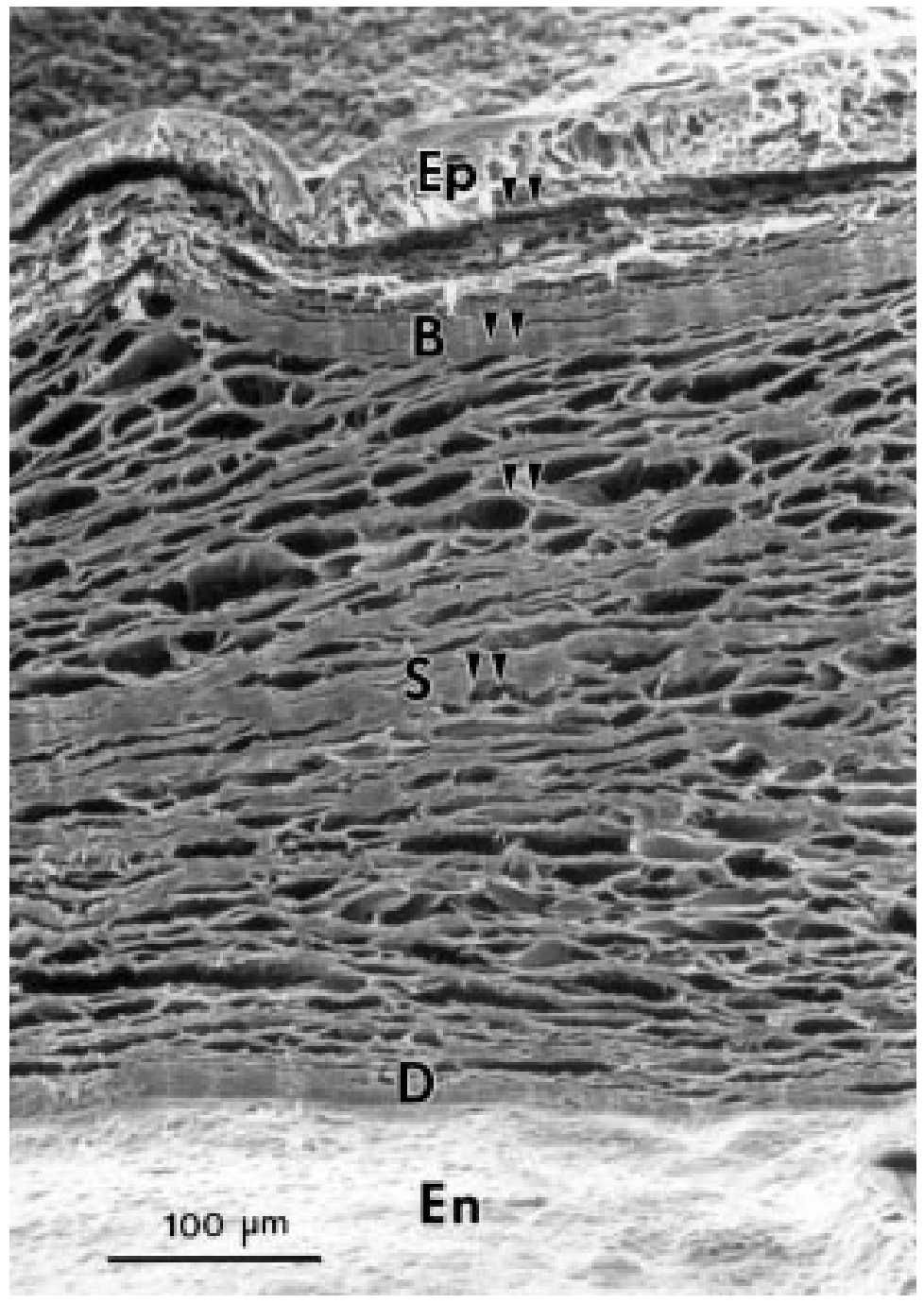

Figure 1 Scanning electron micrograph of the transverse side of a corneal piece. Epithelium (Ep), Bowman's layer (B), stroma (S), Descemet's membrane (D), and endothelium (En). Arrowheads indicate the sites of $x$ ray microanalysis.

purposes. Eyes were enucleated by certified enucleators using aseptic techniques. Antibiotics were not installed in the eye and copious irrigation was not carried out before enucleation. Transportation of the eyes to the cornea bank by BIS took place in a moist chamber on ice. No antibiotics were present in the bathing saline solution. Corneas judged unsuitable for transplantation because of small scars in the optic centre or senile changes in the endothelium ${ }^{23}$ were used for the present experiments.

POVIDONE-IODINE

Solutions were prepared from powdered polyvinylpyrrolidone-iodine (PVP-I, Sigma Chemicals Co, St Louis, MO, USA). For the penetration and decontamination experiments PVP-I was dissolved in demineralised water (Milli Ro4 and Q Reagent Water systems, Millipore, Bedford, MA, USA) in concentrations of $5,20,50$, and $100 \mathrm{mg} / \mathrm{ml}$ and $\mathrm{pH}$ was adjusted to 6.0 with $1 \mathrm{~N} \mathrm{NaOH}$. Solutions were filtered $(0.22 \mu \mathrm{m}$ pore size, Stericup GS, Millipore, Bedford, MA, USA), aseptically divided $(30 \mathrm{ml} / \mathrm{vial})$ in sterile wide necked 50 $\mathrm{ml}$ vials (Greiner GmbH, Frickenhausen, Ger- many), and stored in the dark at room temperature. For toxicity experiments a 10 $\mathrm{mg} / \mathrm{ml}$ PVP-I solution in sterile phosphate buffered saline (PBS), (Azua Pharmacy, Amsterdam, Netherlands) was prepared, filtered (0.22 $\mu \mathrm{m}$ pore size), and aseptically diluted with sterile PBS shortly before use.

\section{$X$ RAY MICROANALYSIS}

Procedure

Corneal tissue (see below) was snap frozen in liquid nitrogen, vacuum freeze dried at $-0^{\circ} \mathrm{C}$ (Virtis Benchtop 5, Virtis Co, Gardiner, NY, USA) and stored on silica gel. The bulk specimens were mounted on a carbon holder and left uncoated. Inspection and analysis was carried out in a Philips SEM 505 scanning electron microscope (Philips Industries, Eindhoven, Netherlands) equipped with an Edax PV 9800 microanalysis system using a windowless ECON detector (Edax PB 9760/26, Edax Ltd, Mahwah, NJ, USA). A high tension of 15 $\mathrm{kV}$ was used throughout and spectra were obtained from spot measurements (spot size $200 \mathrm{~nm}$ ) at the transverse sides of cut corneal pieces in (i) the basal layer of the epithelium, (ii) Bowman's layer, (iii) anterior stroma, and (iv) mid-stroma (arrowheads, Fig 1). The peak to background ratio ( $\mathrm{P} / \mathrm{B}$ ratio) was used to determine the local mass of iodine. The P/B ratio provides an intrinsic absorption correction independent of surface geometry and therefore suitable for analysis of biological bulk specimens. ${ }^{24}$ Specimens were randomly numbered for bias-free monitoring of the presence of iodine. Owing to the dehydrating effect of povidone, however, corneal samples treated with higher concentrations or increased immersion times of PVP-I were nevertheless easily recognised because of the reduced thickness of the cornea.

\section{Tissue selection}

Reliable EDXM quantification of elements in biological materials strongly depends on keeping all variables constant including those of the tissue investigated. ${ }^{24}$ Therefore we decided not to use whole corneas for the different concentrations of PVP-I and different immersion times to be tested but to divide excised corneoscleral buttons into six triangular pieces. In order to see whether the use of pieces reflects the actual situation of rinsing the whole bulb we carried out the following pilot experiment. From paired eyes one globe was immersed in $50 \mathrm{mg} / \mathrm{ml} \mathrm{PVP-I} \mathrm{for} 5$ minutes before excision of the corneoscleral button while from the fellow eye the corneoscleral button was excised, divided into six triangular pieces each, and subsequently immersed in $50 \mathrm{mg} / \mathrm{ml}$ PVP-I for 5 minutes. A control eye and control pieces were immersed in PBS. $x$ Ray spectra were taken from the pieces at the epithelial, anterior stroma, and mid-stroma sites and at comparable sites of the intact corneas. The $x$ ray spectra and $\mathrm{P} / \mathrm{B}$ ratios of $\mathrm{I}$ were nearly identical at these sites in the pieces compared with those in the intact cornea. Although iodine concentrations at the lateral edges and posterior stroma were higher than in the intact cornea under the 


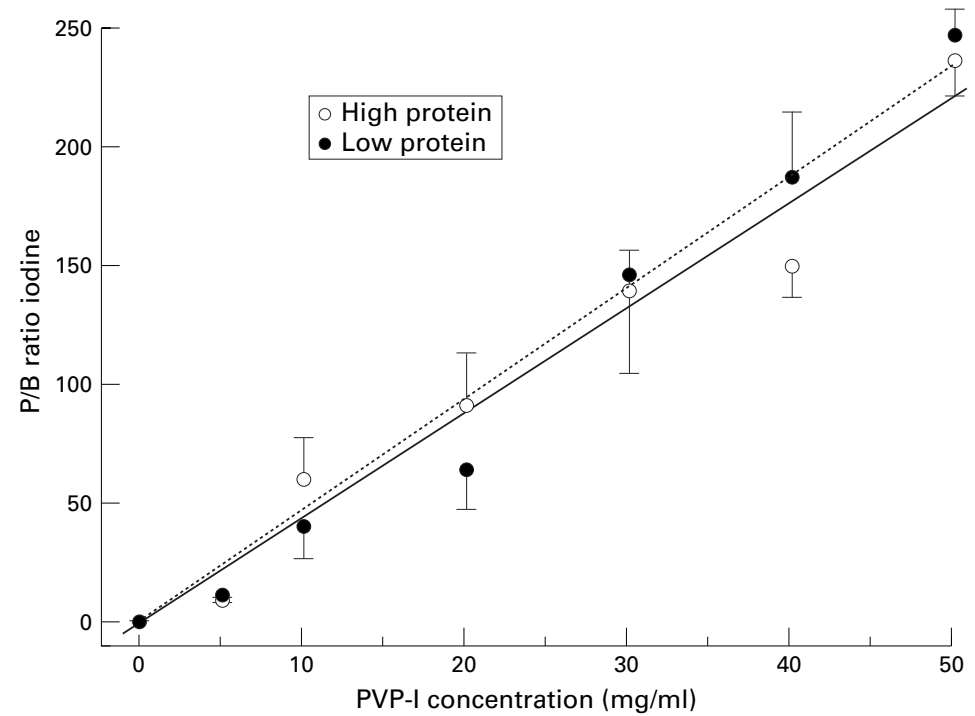

Figure 2 PVP-I concentration and $P / B$ ratio of iodine for standard samples (see Methods) showing the significant correlations for high protein $(R=0.98)$ and low protein $(R=0.99)$ standards. $P / B$ ratios for iodine expressed as mean (SEM) of values assessed in three experiments. relation (Fig 2). The detection limit lies at about $2 \mathrm{mg} / \mathrm{ml}$ PVP-I which corresponds to $0.2 \mathrm{mg} / \mathrm{ml}$ iodine.

MTT ASSAY TO DETECT PVP-I TOXICITY FOR CORNEAL FIBROBLASTS

Tissue

Corneal fibroblasts were obtained from normal human donor eyes as described. ${ }^{27}{ }^{28}$ In short, corneal buttons were excised and cut in small pieces. Three to four corneal pieces were implanted per well of a six well plate (Nunc, Roskilde, Denmark) and incubated with $1 \mathrm{ml}$ Eagle's modified minimum essential medium (EMEM, ICN Biomedicals Inc, Costa Mesa, CA, USA) supplemented with $10 \%$ fetal bovine serum (FBS, Gibco Life Technologies Ltd, Paisley, Scotland), 100 units $/ \mathrm{ml}$ penicillin (Gist Brocades, Leiderdorp, Netherlands), and 50 $\mu \mathrm{g} / \mathrm{ml}$ streptomycin (Biochemie $\mathrm{GmbH}$, Vienna, Austria) at $37^{\circ} \mathrm{C}$. When the pieces adhered firmly to the bottom of the well by the outgrowing cells $5 \mathrm{ml}$ medium per well was added. Medium was renewed twice a week. Outgrowing fibroblasts were subcultured after 25-28 days and fibroblasts of the second passage were stored in liquid nitrogen. Cells were defrosted, subcultured for one passage, and used for experiments. At confluency they were removed from the culture flasks by incubation with a trypsin/EDTA solution for 5 minutes, collected by centrifugation $(200 \times g)$, resuspended in medium, and plated out at $5 \times 10^{4}$ cells per well in 96 well flat bottomed tissue culture plates (Nunc, Roskilde, Denmark). The cells were cultured at $37^{\circ} \mathrm{C}$ in a humidified atmosphere with $5 \%$ carbon dioxide before exposure to freshly prepared PVP-I solutions, varying in concentration from 0.01 to $10 \mathrm{mg} / \mathrm{ml}$ PVP-I. razor blade. The other eye was used as control. Both bulbs were subsequently immersed in various concentrations PVP-I for various times and treated as described above.

Calibration of EDX iodine signals

Contrary to the situation in material sciences, where for quantitation it is mostly sufficient to know the ratio in which the different elements are present in the sample, biological specimens require calibration standards for quantitation preferably resembling the specimen in chemical and physical properties. ${ }^{25}$ In this study standard specimens were prepared from $15 \%$ collagen I from rat tails, equivalent to the amount of collagen in the corneal stroma ${ }^{26}$ and $5 \%$ agarose type VII (Sigma Chemical Co, $\mathrm{St}$ Louis, MO, USA) with a low gelling temperature to substitute for the $5 \%$ non-collagen protein in the stroma and to give the standard specimens some matrix structure. Because corneal stroma may vary locally in protein content at different hydration states, low protein standards with one fifth of the collagen concentration were also prepared. PVP-I was added to this mixture in concentrations of $0-100 \mathrm{mg} / \mathrm{ml}$ before gelling. In three independent experiments a highly significant linear correlation was observed between the PVP-I concentration in the standard specimens and the $\mathrm{P} / \mathrm{B}$ ratios of iodine. The protein content of the standard specimens did not affect this cor-

\section{Procedure}

Cytotoxicity was determined with the MTT assay $^{28-30}$ directly and 48 hours after exposure to PVP-I. The MTT assay basically measures the capacity of mitochondrial enzymes to transform the MTT (3-(4,5 dimethyl thiazoleChemicals Co, St Louis, MO, USA) salt into a formazan product and thus reflects the mitochondrial activity of corneal fibroblasts. After exposure of the cells to the PVP-I solutions (2 minutes, $50 \mu \mathrm{l} /$ well), the cells were carefully washed three times with PBS and $100 \mu \mathrm{l}$ of a culture medium with $2 \%$ FBS was added per well. Directly (acute test) or after 48 hours (delayed test) $10 \mu \mathrm{l}$ of a freshly prepared MTT all wells and plates were incubated at $37^{\circ} \mathrm{C}$ for 4 hours. The MTT formazan reaction product was solubilised by the addition of $200 \mu \mathrm{l}$ acidisopropanol $(0.04 \mathrm{~N} \mathrm{HCl}$ in propanol-2) to the incubation medium without washing steps and overnight incubated at room temperature in the dark. Optical density of the solution was assessed at $560 \mathrm{~nm}$ in a spectrophotometer (I EMS Reader MF, Labsystems, Helsinki, Finland) taking medium with MTT and isopropanol as the blank. Each experiment was performed in eightfold. The experiments were repeated five times. The damage was calcu2yl)-2.5 diphenyyl tetrazolium bromide; Sigma solution ( $5 \mathrm{mg} / \mathrm{ml}$ MTT in PBS) was added to 


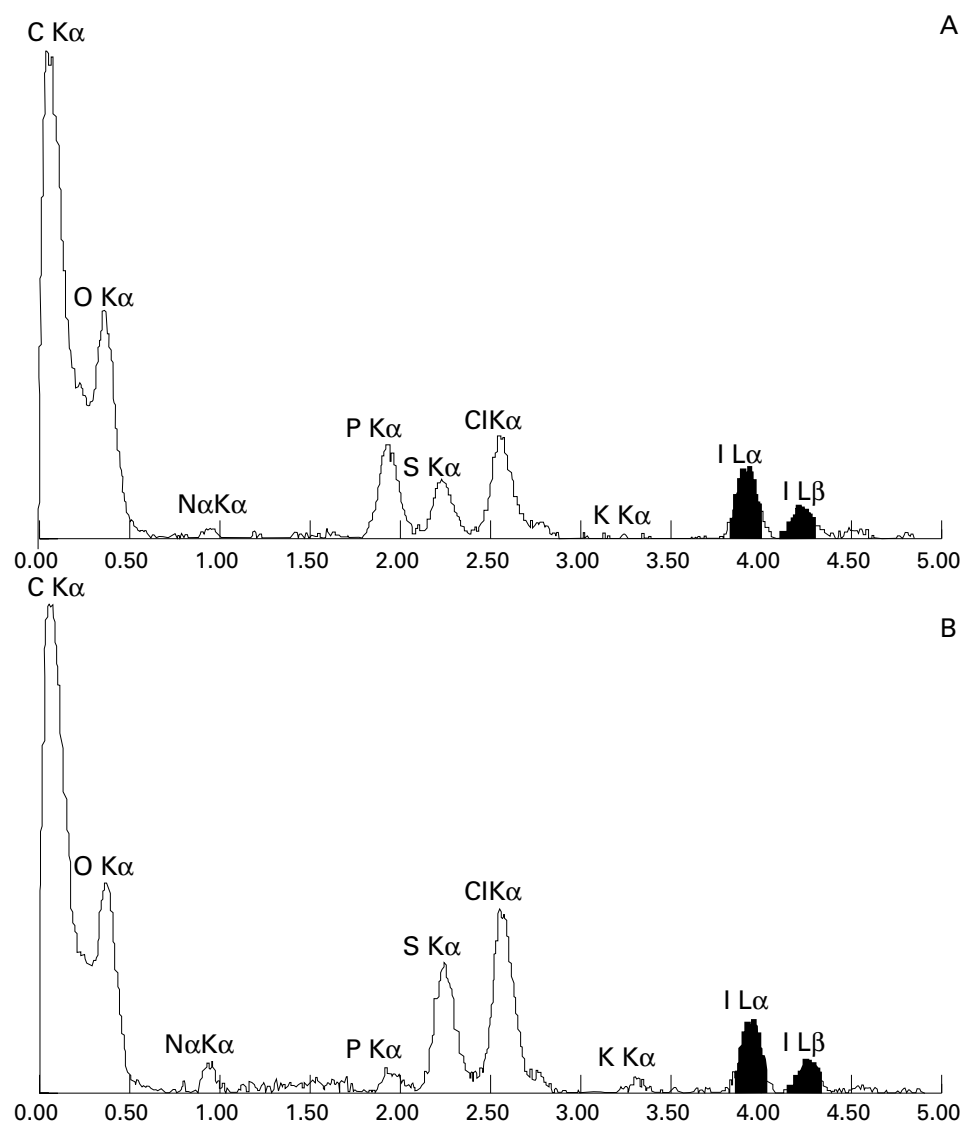

Figure 3 EDAX spectra of a cornea immersed in $50 \mathrm{mg} / \mathrm{ml}$ PVP-I for 10 minutes analysed in the basal layer of the epithelium $(A)$ and anterior stroma (B). For details see text.
A sample of the medium was taken with a sterile syringe through the stopper and incubated on a blood agar plate and thioglycollate-soybean broth (TSB medium) at $37^{\circ} \mathrm{C}$. At the end of the storage period (mean storage time 12 days), and 1 day after transferring the corneas to the transport medium (storage medium supplemented with 5\% dextran $\mathrm{T} 500$ to reverse corneal swelling) samples of the storage and transport medium were taken for sterility control. ${ }^{23}$ Positive cultures were identified by microbiologists (Department Microbiology, Academic Medical Centre, Amsterdam, Netherlands) using standard bacteriological techniques.

CONTROL OF ASEPTIC PROCEDURES USED

To exclude the possibility that the observed contamination of corneas was induced by inproper aseptic techniques and working surroundings, working conditions were evaluated. Corneas $(n=250)$ routinely stored for $14-24$ days and judged unsuitable for transplantation after storage were subsequently processed including light microscopic examination and stored in medium without antibiotics at $31^{\circ} \mathrm{C}$ for another 4 weeks or until contamination become obvious. Tissue contamination should have revealed itself within the first 14-24 days of storage, while improper working conditions would become manifest in the subsequent storage period in the medium without antibiotics.

\section{EFFECTIVENESS OF PVP-I SOLUTIONS}

Donor eyes with corneas unsuitable for transplantation because of scars in the optic centre as observed by slit lamp examination or because of senile changes of the endothelium as observed in the fellow cornea, were used for this part of the study. After removal of adnexal and muscle tissue from the globe using sterile instruments, eyes were rinsed with tap water for 1 minute. After rinsing, the eyes were immersed in different PVP-I solutions (5, 20, 50 , and $100 \mathrm{mg} / \mathrm{ml}$ ) for 2 or 10 minutes, subsequently in $0.5 \%$ sodium thiosulphate solution in PBS for 1 minute and finally rinsed with PBS. After preparation the corneoscleral button was dissected in two pieces. One was incubated in a sterile vial with storage medium as used for routine eye bank storage. The other was incubated in storage medium without antibiotics. Both were stored at $31^{\circ} \mathrm{C}$ for 4 weeks or until contamination became obvious. The groups consisted of 25-30 corneas each. storage solution 90 corneas were divided in two pieces. One piece was stored in a culture medium without the antibiotics penicillin, streptomycin, and nystatin, while the other was stored in medium with these antibiotics. The corneal pieces were incubated at $31^{\circ} \mathrm{C}$ for 4 weeks or until contamination became obvious by change in colour or turbidity of the medium.

MONITORING OF MICROBIAL CONTAMINATION DURING ROUTINE EYE BANKING

Control of tissue

Three days after the onset of storage of excised corneoscleral buttons by organ culture a
Mutiple regression between $\mathrm{P} / \mathrm{B}$ ratios of iodine and PVP-I concentration and immersion time was determined giving regression coefficients and $\mathrm{p}$ values for the slope. Differences in $\mathrm{P} / \mathrm{B}$ ratios in corneas with and without epithelium were compared using the Wilcoxon signed rank sum test. The proportion of contaminated corneas in the different treatment groups were compared using the $\chi^{2}$ test. Level of significance was set at $5 \%$.

\section{STATISTICS}


Figure 4 Penetration of iodine in the epithelium (A), Bowman's layer (B), anterior stroma $(C)$, and mid-stroma (D) of the cornea expressed as $P / B$ ratio for iodine after $\mathrm{mg} / \mathrm{ml}$ PVP-I solution for different time periods up to 30 minutes. Results are representative of five experiments. immersion in 5, 20, 50, 100
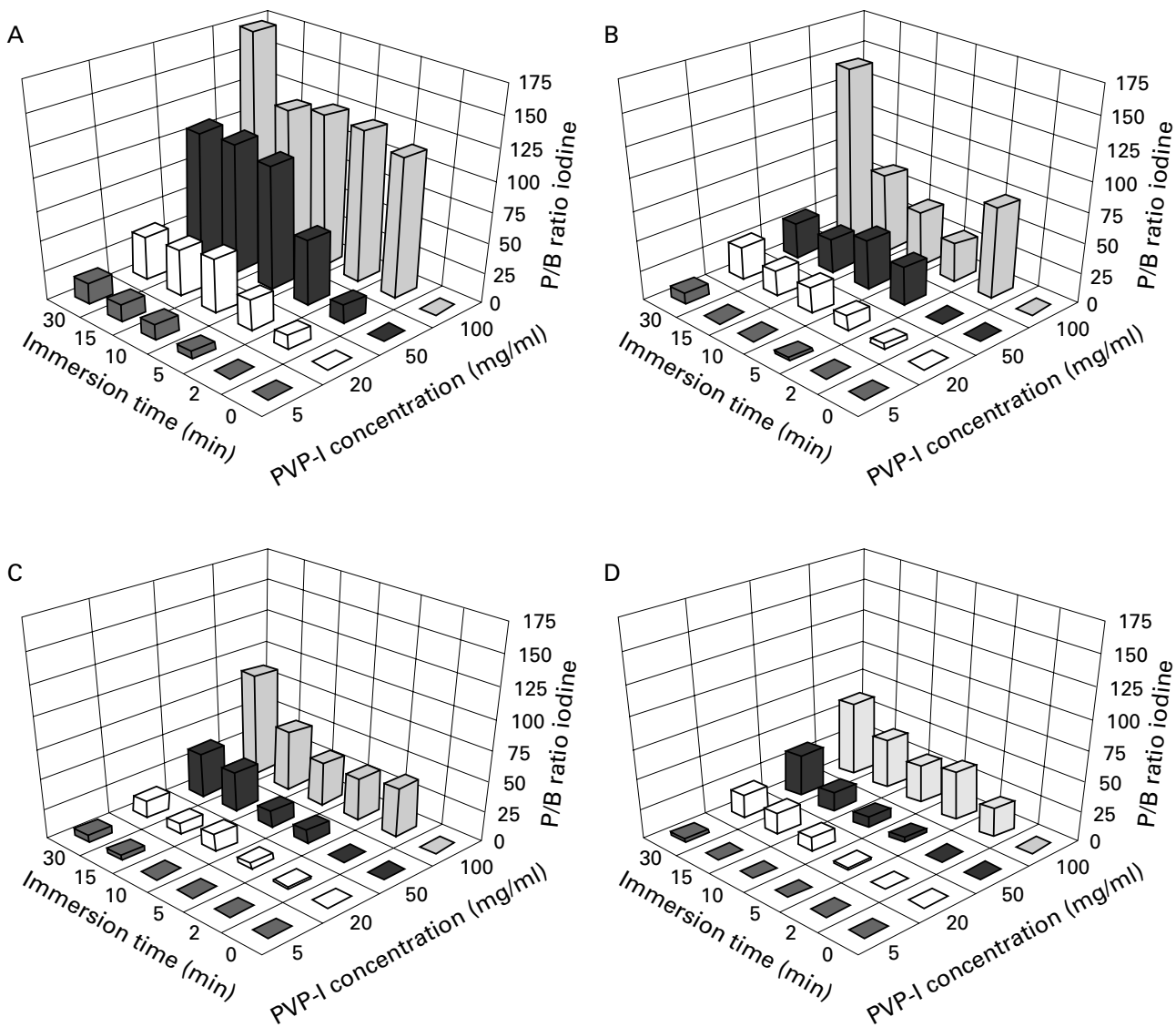

Results

IODINE CONTENT IN CORNEAS ASSAYED BY $X$ RAY MICROANALYSIS

The $x$ ray spectra as exemplified in Figure 3, taken from PVP-I immersed corneas, clearly show the $\mathrm{L} \alpha$ and $\mathrm{L} \beta$ peaks of iodine. Moreover, the $\mathrm{K} \alpha$ peaks of $\mathrm{C}, \mathrm{O}, \mathrm{P}$, and $\mathrm{S}$ are characteristic for biological material when using a windowless detector and indicate the presence of proteins, phospholipids, DNA, and RNA. In line with the higher density of membranes, nuclei, and ribosomes in the epithelium and the higher protein (collagen) content of the stroma the $\mathrm{P}$ peak is more pronounced in the epithelium (Fig $3 \mathrm{~A}$ ) and the $\mathrm{S}$ peak in the stroma (Fig 3B). There is no

Table 1 Effect of epithelial removal on the $P / B$ iodine ratio

\begin{tabular}{|c|c|c|c|c|c|}
\hline \multirow{2}{*}{\multicolumn{2}{|c|}{ Concentration PVP-I solution * }} & \multicolumn{4}{|c|}{$P / B$ ratio iodine (mean $(S D)$ ) } \\
\hline & & \multicolumn{2}{|l|}{$20 \mathrm{mg} / \mathrm{ml}$} & \multicolumn{2}{|l|}{$100 \mathrm{mg} / \mathrm{ml}$} \\
\hline Exposure timet & Corneal layer & $\begin{array}{l}\text { with } \\
\text { epithelium }\end{array}$ & $\begin{array}{l}\text { epithelium } \\
\text { removed }\end{array}$ & $\begin{array}{l}\text { with } \\
\text { epithelium }\end{array}$ & $\begin{array}{l}\text { epithelium } \\
\text { removed }\end{array}$ \\
\hline \multirow[t]{4}{*}{2 minutes } & Epithelium & $11(2)$ & & $115(19)$ & \\
\hline & Bowman's layer & $6(4)$ & $22(4)$ & $76(20)$ & $40(6)$ \\
\hline & Anterior stroma & $2(0)$ & $18(2)$ & $41(9)$ & $40(5)$ \\
\hline & Mid-stroma & 0 & $13(5)$ & $39(7)$ & $33(6)$ \\
\hline \multirow[t]{4}{*}{10 minutes } & Epithelium & $46(13)$ & & $126(22)$ & \\
\hline & Bowman's layer & $23(7)$ & $25(7)$ & $47(15)$ & $75(26)$ \\
\hline & Anterior stroma & $15(4)$ & $18(2)$ & $36(8)$ & $41(11)$ \\
\hline & Mid-stroma & $12(5)$ & $14(4)$ & $32(17)$ & $27(9)$ \\
\hline \multirow[t]{4}{*}{30 minutes } & Epithelium & 37 (11) & & $173(18)$ & \\
\hline & Bowman's layer & $19(7)$ & $69(17)$ & $145(73)$ & $107(26)$ \\
\hline & Anterior stroma & $15(9)$ & $19(2)$ & $87(22)$ & $74(13)$ \\
\hline & Mid-stroma & $9(8)$ & $13(3)$ & $61(15)$ & $62(14)$ \\
\hline Signed rank test & & $\mathrm{p}<0.05$ & & $\mathrm{p}>0.05$ & \\
\hline
\end{tabular}

*Data other concentrations $(10$ and $50 \mathrm{mg} / \mathrm{ml}$ ) not shown.

†Data other exposure times (5 and 15 minutes) not shown.

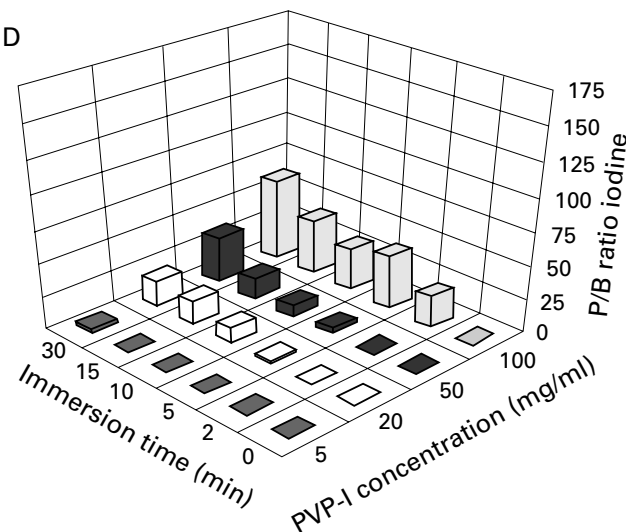

reasonable explanation for the high $\mathrm{K} \alpha$ peak of $\mathrm{Cl}$ also found in untreated material. This must be an artefact although, at present, of unknown origin.

The $\mathrm{P} / \mathrm{B}$ ratios of I $\mathrm{L} \alpha$ at different corneal sites, epithelium, Bowman's layer, anterior stroma, mid-stroma (see Fig 1), correlated significantly with PVP-I concentration and immersion periods (Fig 4A-D respectively). At the lowest concentration, iodine is observed in the epithelium at 5 minutes (Fig 4A) and at 30 minutes some iodine is found in the stroma (Fig 4C, D). After 2 minutes' exposure of the higher concentrations $(20,50$, and $100 \mathrm{mg} / \mathrm{ml})$ iodine is observed in Bowman's layer. Penetration of iodine into the stromal layers already occurs after 5 minutes' exposure to the highest concentrations (50 and 100 PVP-I $\mathrm{mg} / \mathrm{ml}$ ). Using the $\mathrm{P} / \mathrm{B}$ ratio of the PVP-I standard curves (Fig 2) the amount of PVP-I maximally penetrating Bowman's layer, anterior, and mid-stroma is equivalent to about 35,25 , and $15 \mathrm{mg} / \mathrm{ml}$ PVP-I respectively after 30 minutes' immersion to $100 \mathrm{mg} / \mathrm{ml}$ PVP-I.

The $\mathrm{P} / \mathrm{B}$ ratios of iodine in the stromal layers of corneas from which the epithelium was removed were not significantly different from those found with the epithelium present (sign test) at concentrations of 50 and 100 PVP-I $\mathrm{mg} / \mathrm{ml}$. With the 5 and $20 \mathrm{mg} / \mathrm{ml} \mathrm{PVP-I}$ solutions, however, significantly larger $\mathrm{P} / \mathrm{B}$ ratios were observed (signed rank test). However, the ratios were small (Table 1) and the mean of the standard variations of six measurements in one corneal layer was about $30 \%$. 


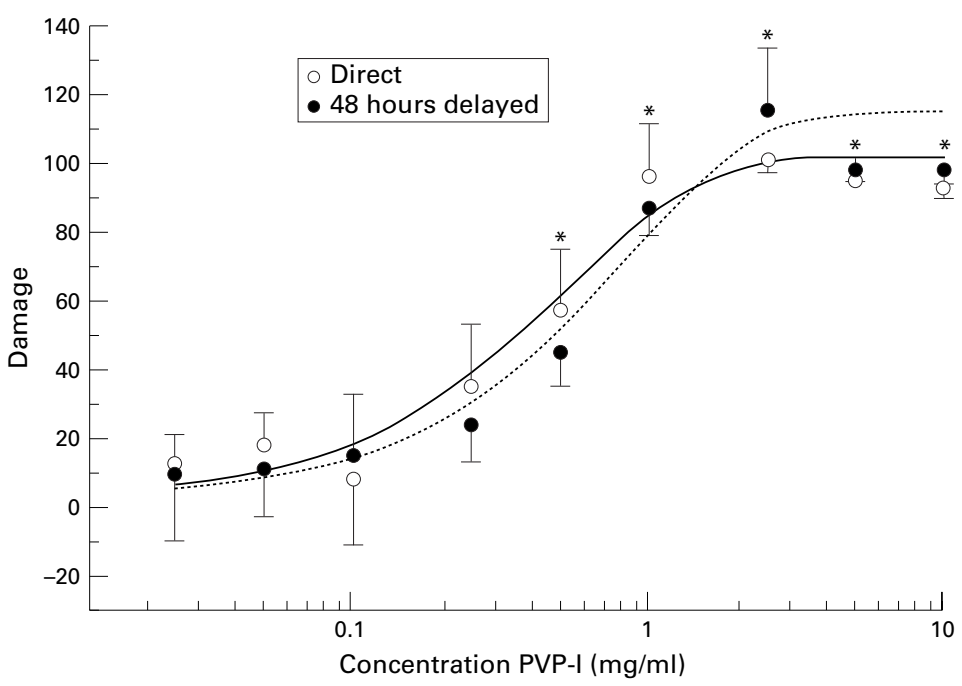

Figure 5 Dose/response curve of PVP-I solutions for human corneal fibroblasts. Damage was assessed with the MTT assay directly after exposure of the cells to the PVP-I and 48 hours later. Mean (SD) of the means obtained in five experiments in eightfold. Asterisks indicate damage significantly different from controls.

Table 2 Effect decontamination procedure on surface contaminants

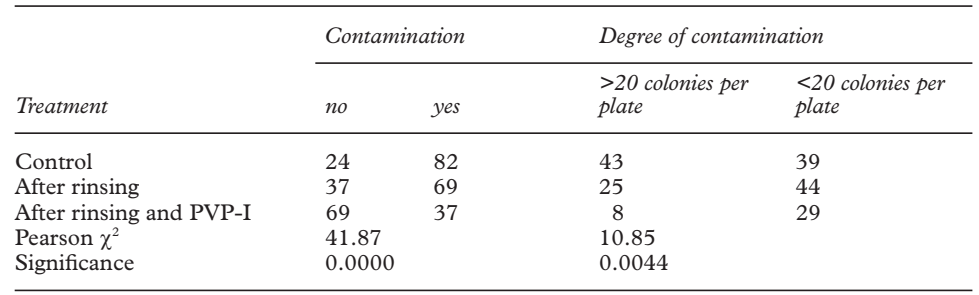

TOXICITY OF PVP-I FOR CORNEAL FIBROBLASTS Significant damage of the corneal fibroblasts was observed at a concentration of $0.25 \mathrm{mg} / \mathrm{ml}$ PVP-I for 2 minutes (Fig 5). Lower concentrations gave no significant damage, neither directly nor 48 hours after immersion. Cell damage increased with increasing PVP-I concentrations. Nearly total damage was observed at concentrations of $2.5 \mathrm{mg} / \mathrm{ml}$ PVP-I and more both in the direct and in the delayed test. Substance concentrations at half maximum cytotoxicity (LC 50) calculated from the doseresponse curves, were 0.4 and $0.6 \mathrm{mg} / \mathrm{ml}$ for the direct and delayed test respectively (Sigmoidal fiT, Fig 5).

MONITORING THE EFFECTIVENESS OF DECONTAMINATION PROCEDURES USED IN ROUTINE EYE BANKING

On arrival 82 of the 106 eyes were found to be contaminated with surface contaminants (Table 2). After rinsing with tap water the ratio of contaminated eyes decreased to 69 out of 106 , while the number of colonies observed also decreased. Most cultures were pure consisting of one microbial strain. After treatment with $0.5 \%$ PVP-I for 2 minutes the ratio of contaminated eyes decreased further to 37 out of 106 (Table 2).

From the corneal pieces stored without and with antibiotics 34 out of 90 (38\%) and four out of $90(4 \%)$ turned out to be contaminated, respectively.
Table 3 Effectiveness of PVP-I

$\%$ corneas not contaminated $\left(n / n_{\text {totaa }}\right)$

\begin{tabular}{lll}
\hline & \multicolumn{2}{c}{ Exposure time (minutes) } \\
\cline { 2 - 3 } & 2 & 10 \\
\hline PVP-I $5 \mathrm{mg} / \mathrm{ml}$ & $69(18 / 26)$ & $63(17 / 27)$ \\
PVP-I $20 \mathrm{mg} / \mathrm{ml}$ & $68(15 / 22)$ & $83(20 / 24)$ \\
PVP-I $50 \mathrm{mg} / \mathrm{ml}$ & $65(15 / 23)$ & $66(19 / 29)$ \\
PVP-I $100 \mathrm{mg} / \mathrm{ml}$ & $67(16 / 24)$ & $80(20 / 25)$ \\
\hline
\end{tabular}

MONITORING OF MICROBIAL CONTAMINATION DURING ROUTINE EYE BANKING

Control of tissue

Three per cent of corneas stored routinely by organ culture in the bank (1994-6 follow up study of 4000 corneas) turned out to be contaminated. Contaminants were Staphylococcus epidermidis (36\%), Pseudomonas sp (27\%), Escherichia coli (9\%), and Bacillus sp (8\%). Fungal contamination was less than $0.6 \%$. Most contaminants (95\%) were detected within a 3 day storage period. However, some escaped detection in the medium sample and showed up around day 10 in the storage solution or in the transport solution. No difference in contamination rate was observed between corneas accepted for transplantation or judged unsuitable.

Control of procedure

Corneas $(n=250)$ were routinely processed, incubated for 14-24 days and removed from this medium for evaluation of the endothelium. They were returned to medium without antibiotics to discriminate whether contamination of corneas during storage is due to remaining contaminants or is induced by inadequate working conditions. Not one single cornea turned out to be contaminated.

EFFECTIVENESS OF PVP-I SOLUTIONS

Eyes were rinsed with tap water as usual and then submersed for 2 or 10 minutes in different concentrations of PVP-I (5, 20, 50, and 100 $\mathrm{mg} / \mathrm{ml}$ ). After excision the corneoscleral buttons were stored in medium without antibiotics. The effectiveness of the decontaminating procedure was expressed as percentage corneas observed free of contamination. No significant differences were observed between the different groups (Table 3). With a sample size of about 25 for each group a $20 \%$ difference between the treatment groups can be detected in $90 \%$ of trials. Staphylococcus epidermidis was again the most common contaminant (43\%).

\section{Discussion}

After immersion of corneal tissue in PVP-I solutions as part of a decontamination process, iodine was found to penetrate the corneal tissue. Depending on concentration and exposure time iodine was found from the basal epithelium to half way in the stromal depth. At treatment with $5-50 \mathrm{mg} / \mathrm{ml}$ PVP-I for 2 minutes the iodine was virtually absent in the stromal layers. Quantitative $x$ ray microanalysis of biological specimens has some intrinsic problems - for example, the need of suitable standards and the relatively few established 
methods for quantitative analysis of bulk specimens. ${ }^{24}{ }^{25}$ In order to get an indication of the amount of iodine penetrated, standards were prepared resembling the composition of the corneal stroma. Because PVP-I exerts a dehydrating effect on the corneal stroma and postmortem corneas vary in hydration state, standards with high and low protein content were used. No differences were observed between the high and low protein standards provided the amount of iodine was expressed as the peak to background ratio. This $\mathrm{P} / \mathrm{B}$ ratio was linearly correlated with the iodine content of the standards. The minimum amount of iodine detected corresponds to $0.2 \mathrm{mg} / \mathrm{ml}$ (2 $\mathrm{mg} / \mathrm{ml}$ PVP-I). This is far above the claimed limit of detectability of $10^{-14} \mathrm{~g}^{31}$ A reason for this discrepancy might have been that conditions are not optimal for pieces of corneal tissue.

It was expected that exposure of both the epithelial and endothelial surface to the PVP-I solution would increase the stromal concentration of iodine compared with epithelial exposure only as is the case with immersion of whole eyes. In the pilot experiment using 50 $\mathrm{mg} / \mathrm{ml}$ PVP-I for 5 minutes only, this was not found. The main reason for this could be that the values are close to the detection limit of the EDX procedure and that additional effects remain undetected. However, in the further experiments with higher PVP-I concentrations and longer immersion times a gradient was always observed from epithelium, through Bowman's layer to anterior and mid-stroma. This suggests that the PVP-I penetration measured in the corneal pieces indeed reflects the actual situation after immersion of the whole eye. The rate of PVP-I penetration seems not only to be governed by the concentration gradient, the solute permeability coefficient and the surface area available, but also by structural barriers which may be different at the epithelial, endothelial, Bowman's, and Descemet linings.

The variation of $\mathrm{P} / \mathrm{B}$ ratios in measurements within one cornea was considerable. A detailed quantification of the amount of iodine present in the cornea was therefore not possible. The results were, however, consistent in the different experiments.

Removal of the epithelium had no influence on penetration with the higher PVP-I solutions (50 and $100 \mathrm{mg} / \mathrm{ml}$ ), whereas more iodine was observed in Bowman's layer and stroma with the lower PVP-I concentrations. This suggests that with increasing concentrations of PVP-I the barrier function of the epithelium is destroyed.

EDXM does not allow us to discern whether the iodine was present as reactive "free" iodine $\left(\mathrm{I}_{2}\right)$, as "tamed" iodine still complexed to the PVP, or as iodide after chemical reduction.

PVP-I causes dose related damage of stromal fibroblasts in vitro. Maximal damage occurred in both the acute test and the delayed test with $0.5 \mathrm{mg} / \mathrm{ml} \mathrm{PVP-I,} \mathrm{indicating} \mathrm{that} \mathrm{the}$ effect of PVP-I is not a temporarily reversible reduction of enzyme activity. Similar toxicity levels of PVP-I were found for corneal endothelium, when PVP-I was added to the Dexsol solution for storage of corneoscleral buttons. $^{32} 33$ Of the preoperative antiseptics used in ophthalmic surgery, PVP-I turned out to be the only one not toxic for the epithelium. ${ }^{21}$ This explains why decontaminating procedures with PVP-I solutions of 5-100 $\mathrm{mg} / \mathrm{ml}$ for $2-5$ minutes can be applied without affecting subsequent epithelial regrowth during organ culture of the corneoscleral button. An effect on the fibroblasts, however, could not be excluded in that study. ${ }^{21}$ Stromal maculation and staining of fibroblasts with trypan blue when PVP-I solutions of over $25 \mathrm{mg} / \mathrm{ml}$ were used for longer than 2 minutes have been described. ${ }^{12}$ The present study demonstrates that iodine indeed penetrates the cornea. The amount in the stroma is low compared with that in the epithelium but it is apparently sufficient to cause fibroblast damage and death with immersion periods of more than 2 minutes and concentrations above $5 \mathrm{mg} / \mathrm{ml}$ PVP-I.

Because of its broad action spectrum and low toxicity for the epithelium PVP-I may be a useful treatment for corneal ulcers. ${ }^{22}$ In that case toxic effects on the fibroblasts, because of its penetration into the corneal tissue, are of minor importance.

In routine eye banking decontamination of human donor eyes with $5 \mathrm{mg} / \mathrm{ml}$ PVP-I for 2 minutes significantly reduces the viability of microbial surface contaminants and thus the risk of corneal tissue contamination. However, it does not eliminate all contaminating microbes. After decontamination procedures $36 \%$ of the eyes remained positive in microbiological tests. Higher concentrations of PVP-I and longer immersion periods do not further reduce the percentage of contaminated corneas. These results are in agreement with studies demonstrating more rapid bactericidal action of diluted solutions of PVP-I than a full strength $10 \%$ solution. ${ }^{17}{ }^{18}$ The free iodine, the reactive component of the PVP-I complex, is constantly released in small amounts, remains in equilibrium with the complex, and undergoes chemical reactions characteristic of iodine until the available iodine is exhausted. It follows a bell shaped curve with a maximum level in a $7 \mathrm{mg} / \mathrm{ml}$ solution. ${ }^{17}$ The bactericidal activity of PVP-I decreases by exposure to organic substances. Therefore, removal of excess tissue from the eye such as remnants of muscles, conjunctiva, and orbital fat, is important for optimal results.

The rate of contamination among eye banks using organ culture varies from $0.53 \%{ }^{34}$ to $5 \%^{35}$ and a mean percentage of $3.5 \%$ is reported for banks in Europe. ${ }^{19}$ The cause of death and the time elapsed from death to enucleation may have a marked influence on the risk of contamination. Improved removal of contaminants early in the process to minimise the contaminating microbial load and the amount of bacterial waste products such as endotoxins in the storage solution is of course advantageous. $^{36}$

Antibiotics in the storage solution were shown to be needed as a last step of the decon- 
tamination procedure to reduce the microbial risk to an acceptable level. One approach is to accept a certain level of contamination with a conventional penicillin/streptomycin containing medium. If, in that case, an organism resistant to the antibiotics is present in low numbers and escapes detection during the sterility controls a wide range of more effective antibiotics is still available for the clinician in cases of ophthalmitis. Another approach is to keep the contamination rate at nearly zero levels with wide spectrum and powerful antibiotics such as amicacin. ${ }^{19}$ However, in that case multiresistant microbes may be induced in organ culture surroundings favouring antibiotic resistance development. In case these microbes enter the eye after grafting, antibiotic treatment is not available.

After immersion PVP-I remains on the outside of the bulbus. With increasing concentrations the viscosity of the PVP-I solution increases and it becomes more difficult to remove the reactive iodine before preparation of the corneoscleral button. During excision of the corneoscleral button PVP-I may inadvertently penetrate the anterior chamber and may damage the endothelium. The sodium thiosulphate solution advocated to reduce the activity of the remaining free iodine is useful in these cases and might itself inhibit bacterial growth. ${ }^{37}$

It is evident that the effectiveness of decontamination procedures can only be evaluated correctly if the working conditions in the bank, such as aseptic handling for storage and evaluation of the corneoscleral buttons, do not add to the risk of contamination. This was shown to be the case in our cornea bank.

The present study allows the following conclusions:

(i) rinsing with tap water and immersion in PVP-I solution together with classic antibiotics in the storage solution reduce the contamination rate of human donor corneas to $3 \%$ under the conditions studied;

(ii) PVP-I $(0.5 \%) 5 \mathrm{mg} / \mathrm{ml}$ for 2 minutes is sufficient for maximal decontaminating effect without the risk of iodine penetrating the corneal stromal layers and damaging corneal fibroblasts;

(iii) before considering the introduction of more powerful antibiotics in the storage solution, careful monitoring of contamination levels during the storage process will reveal whether reduction can be expected from other collection methods, improved working conditions, and repeated decontamination procedures.

The authors thank Mr B Willekens for performing the EDX analyses, the staff of the cornea bank for making tissue available and performing the culture experiments, the Department of Immunology for its kind gift of collagen I, the Department of Photography for preparation of the figures, and the Department of Microbiology, Academic Medical Centre, Amsterdam for determination of the contaminating microbes.

1 Rollins HJ, Stocker FW. Bacterial flora and preoperative treatment of donor corneas. Am $\mathcal{f}$ Ophthalmol $1965 ; 59 \cdot 247-9$

2 Keates RH, Mishler KE, Riedinger D. Bacterial contamination of donor eyes. Am F Ophthalmol 1977;84:617-20.
3 Badenoch PR, Alfrich SJ, Wedding TR, et al. Effectiveness of a decontamination method for donor corneas. Br $\mathcal{f}$ Ophthalmol 1988;72:225-7

4 Garweg J, Böhnke M, Sabow D, et al. Bacterial contamination of corneal tissue: origin of organisms. Fortschr Ophthalmol 1989;86:287-90.

5 Boberg-Ans J, Badsberg E, Rasmussen J. Frequency of infection in donor eyes post mortem. $\mathrm{Br} \mathcal{F}$ Ophthalmol 1962;46:365-8.

6 Rycroft P. Method for the preservation and sterilization of resh donor material for full-thickness keratoplasty by ramycetin. Br f Ophthalmol 1965;49:251-8.

7 Polack FM, Locather-Khorazo D, Guiterrez E. Bacteriologic study of "donor" eyes. Arch Ophthalmol 1967;78:21925.

8 White JH. Fungal contamination of donor eyes. $\mathrm{Br} \mathrm{f}$ Ophthalmol 1969;53:30-3.

9 Gopinathan U, Reddy MK, Nadkarni MS, et al. Antimicrobial effect of ciprofloxacin, povidone-iodine, and gentamicin in the decontamination of human donor globes. Cornea 1998;17:57-61.

10 Docter D, Hughes I. Prophylactic use of neosporin for donor eyes. Am f Ophthalmol 1958;40:351-3.

11 Goldman KN, Centifanto Y, Kaufman HE, et al. Prevention of surface bacterial contamination of donor eyes. Arch Ophthalmol 1978;96:2277-80.

12 Sperling S, Sørensen IG. Decontamination of cadaver corneas. Acta Ophthalmol 1981;59:126-33.

13 Pardos GJ, Gallagher MA. Microbiological contamination of donor eyes. Arch Ophthalmol 1982;100:1611-3.

14 Nash RW, Lindquist TD, Kalina RE. An evaluation of saline irrigation and comparison of povidone-iodine and antibiotic in the surface decontamination of donor eyes. Arch Ophthalmol 1991;109:869-72.

15 Ritter E, Götze J, Trute K, et al. Bacterial contamination of corneal donor material post mortem. Klin Monatsbl Augenheilkd 1990;196:70-5.

16 Mindrup EA, Dubbel PA, Doughman DJ. Betadine deconMindrup EA, Dubbel PA, Doughman DJ. Betadine

17 Zamora JL. Chemical and microbiologic characteristics and toxicity of povidone-iodine solutions. Am f Surg 1986;151: 400-6.

18 Berkelman RL, Holland BW, Anderson RL. Increased bactericidal activity of dilute preparations of povidone-iodine solutions. F Clin Microbiol 1982;15:635-9.

19 Pels E, Tullo AB. Directory of European eye banks. 6th ed. Aachen Germany: EEBA Meeting, 1998

20 Wille H. Assessment of possible toxic effects of polyvinylpyrrolidone-iodine upon the human eye in conjunction with cataract extraction. Acta Ophthalmol 1982;60:955-60.

21 MacRae SM, Brown B, Edelhauser HF. The corneal toxicity of presurgical skin antiseptics. Am $\mathcal{f}$ Ophthalmol 1984;97:221-32.

22 York KK, Miller S, Gaster RN, et al. Polyvinylpyrrolidoneiodine: corneal toxicity and epithelial healing in a rabbit model. 7 Ocular Pharmacol 1988;4:351-8.

23 Pels E, Schuchard Y. Organ culture and endothelial evaluation as a preservation for human corneas. In: Brightbill FS, ed. Corneal surgery. 2nd ed. St Louis: Mosby, 1993:622-32.

24 Roomans GM. Quantitative X-ray microanalysis of biological specimens. F Electron Microscopy Technique 1988;9:1943.

25 Roomans GM. Problems in quantitative X-ray microanalysis of biological specimens. Scanning Electron Microscopy 1980;II:309-20

26 Maurice DM. The cornea. In: Davson H, ed. The eye. Vol I. London: Academic Press, 1969:489-600.

27 Fitzgerald PH, Rosman I. Sex chromosome loss and clones characterized by autosomal abnormality in cultured corneal fibroblasts of man. Cytogenet Cell Genet 1984;38: 29-33.

28 Hoppenreijs VPT, Pels E, Vrensen GFJM, et al. Plateletderived growth factor: receptor expression in corneas and effects on corneal cells. Invest Ophthalmol Vis Sci 1993;34: 637-49.

29 Mosmann T. Rapid colorimetric assay for cellular growth and survival: application to proliferation and cytotoxicity assays. F Immunol Methods 1983;65:55-63.

30 Pels E, Nuijts RMMA, Breebaart AC, et al. Rapid quantitative assay for corneal endothelial cell viability in vitro. Cornea 1993;12:289-94.

31 Hall TA. Biological X-ray microanalysis. $f$ Microsc 1979; 117:145-63.

32 Garcia-Ferrez FJ, Murray PR, Pepose JS. Corneal endothelial cytotoxicity of dexsol corneal storage medium supplemented with povidone-iodine. Arch Ophthalmol 1992;110: 1519-20.

33 Klyce SD, Beuerman RW. Structure and function of the cornea. In: Kaufman HE, Barron BA, McDonald MB, et al, eds. The cornea. New York: Churchill Livingstone, 1988:354.

34 Hagenah M, Böhnke M, Engelmann K, et al. Incidence of bacterial and fungal contamination of donor corneas preserved by organ culture. Cornea 1995;14:423-6.

35 Armitage WJ, Easty DL. Factors influencing the suitability of organ-cultured corneas for transplantation. Invest of organ-cultured corneas for
Ophthalmol Vis Sci 1997;38:16-24

36 Sobottka Ventura AC, Engelmann K, Dahinden C, et al. Endotoxins modulate the autocrine function of organ cultured donor corneas and increase the incidence of endothelial cell death. Br f Ophthalmol 1997;81:1093-8

37 Gross A, Cofone L, Huff MB. Iodine inactivating agent in surgical scrub testing. Arch Surg 1973;106:175-8. 